\title{
Effect of environmental factors on how older pedestrians detect an upcoming step
}

\author{
T-J Cheng $\mathrm{PhD}^{\mathrm{a}}$, B Yang $\mathrm{PhD}^{\mathrm{b}}$, C Holloway $\mathrm{PhD}^{\mathrm{c}}$ and $\mathbf{N}$ Tyler $\mathrm{PhD}^{\mathrm{a}}$ \\ ${ }^{a}$ Accessibility Research Group, Department of Civil, Environmental and Geomatic \\ Engineering, University College London, London, UK \\ b School of Architecture and Urban Planning, Harbin Institute of Technology, Shenzhen, \\ China
}

${ }^{c}$ Department of Computer Science, University College London, London, UK

Short title: Detecting an upcoming step

Received 26 June 2016; Revised 23 August 2016; Accepted

The relationships between environmental features and older people's ability to safely move around a complex pedestrian environment are, as yet, poorly understood. Specifically, the impact of light levels on trip hazard detection during walking has received relatively little attention. This study investigates the effect of illuminance on people's ability to detect steps of different heights in a laboratory-based controlled environment. Sixteen young and fifteen older participants walked along a 13.2m walkway towards an either an ascending or descending step at 200 lx or 4 Ix light levels. Trial time, gaze behaviour, and distance at which the step was first visually fixated (detection distance) were measured using an eyetracker. It was found that both the trial time and detection distance of older participants were affected by light level whereas the fixation number and fixation duration of young participants were affected by step-height. Shorter detection distance, greater number of fixations and longer fixation duration were found among older participants as opposed to young participants. The results suggest that the processing efficiency for visual information on an upcoming step is slower among older people than among young people. This implies that the vulnerability of older pedestrians maybe be reduced if better lighting or a simplified visual environment is provided.

Addresses for correspondence: Tsu-Jui. Cheng, Accessibility Research Group, Department of Civil, Environment and Geomatic Engineering, University College London, Gower Street, 
London WC1E 6BT, United Kingdom.

E-mail: tsu-jui.cheng.10@ucl.ac.uk

and B.Yang, School of Architecture and Urban Planning, Harbin Institute of Technology (Shenzhen), Shenzhen 518055, China.

E-mail: yangbiao@hitsz.edu.cn 


\section{Introduction}

The accessibility of the built environment is fundamental to an older individual's mobility as well as the quality of life, especially when as a pedestrian ${ }^{1-4}$. However, with ageing and the resultant degeneration in vision and balance mechanisms, older people become more susceptible to tripping over environmental hazards, such as kerbs, or small steps.

Visual information is used by pedestrians to perform obstacle detection, orientation, and to allow planning of subsequent foot placements. The provision of visual information to inform this planning process is fundamentally affected by street light levels ${ }^{5-7}$ and this is particularly important as people become old. It is estimated that for an average adults at their age of 60 years, the illuminance needed to navigate a typical home indoor environment would be three times as much as that needed by an average 20 -year-old ${ }^{8}$. Furthermore, visual function also degenerates with age-related diseases, such as cataracts, glaucoma, macular degeneration and diabetes ${ }^{9}$, exacerbating the age-related reductions in contrast sensitivity, stereoacuity and colour sensitivity ${ }^{10}$.

The Manual for Streets $2{ }^{11}$ bases their recommendation for lighting on the guidance contained in the British ${ }^{12}$ and European Standards ${ }^{13}$. Both of these two standards apply a system called 'lighting classes' to determine the recommended illuminance according to the type of street, and pedestrian and residential areas are defined as 'S-series'. The recommended minimum illuminance of this S-series ranges between 2 to 15 lux. Being consistent with this recommendation, the Inclusive Mobility guidelines ${ }^{14}$ recommend an average illuminance between 3.5 and 10 lux for general street lighting. However, when obstacles, such as steps or stairs, are present, a minimum illuminance of 200 lux is recommended as acceptable.

Obstacles that require a person to go up or down a single step are commonly encountered by pedestrians, for example kerbs and raised paving slabs due to pavement defects. It is commonly acknowledged that these represent a barrier and possible trip hazard to people and one which those with mobility impairments find difficult to overcome ${ }^{1}$. Therefore, the Inclusive Mobility guidelines ${ }^{14}$ suggest a minimum height of $125 \mathrm{~mm}$ for kerbs. The UK Pavement Management System ${ }^{15}$ suggests that a pavement defect over 30 $\mathrm{mm}$ in height can be classified as being severe. However, guidelines on light levels and on suggested step-heights in the pedestrian environment are hardly based on empirical evidence considering the inclusion of older people. 
Past studies simulating pedestrian environment in controlled laboratories have explored gaze behaviour in the approach phase to examine how people use visual information to detect obstacles while walking ${ }^{16,17}$. The approach phase is the distance people walk over before encountering obstacles. However, the length of the approach phase varies between studies, depending on the limits of each study. Gaze behaviour reflects the demand from the central nervous system (CNS) for information needed to plan and correct footsteps, especially when walking across complex terrain ${ }^{18}$. Patla and Vickers ${ }^{16}$ found that people fixate on an obstacle one or two footsteps before the obstacle and that the frequency of obstacle fixation increases with the obstacle's height. Fotios and Cheal ${ }^{19}$ studied the probability of obstacle detection to a variety of combinations of illuminance (between 0.2 and 20 lux) and raised obstacles (between 0.4 and $7.79 \mathrm{~mm}$ ) in a static laboratory setting using a forced-choice method between young and older age groups, and found that although there was a between-group difference in the probability of detection at 0.2 lux, the probability reached a plateau for both age groups between 2 and 20 lux. Fotios and Cheal's follow-up study ${ }^{20}$ repeated the same approach in young participants to further establish the optimum lighting level of 2 lux. In one of the most recent papers, Uttley et $a{ }^{6}$ studied the ability of detecting peripheral obstacles under a variety of combinations of illuminance (between 0.2 and 20 lux) and raised obstacles (between 0.5 and $28.4 \mathrm{~mm}$ ) during treadmill walking. An age affect was found at the lowest illuminance of 0.2 lux with the younger group having a higher correct identification rate than the older group. The detection probability increased as the illuminance became higher and a plateau was reached at 2 lux.

Walking is a complex and multifactorial task ${ }^{21,22}$. Both physiological and neuropsychological factors are correlated to gait instability, and age-related changes can further affect the physiological functions. This paper reports a new approach to investigate the ability to detect an upcoming step by incorporating walking along a path of length $13.2 \mathrm{~m}$. This approach addresses the potential limitations of past studies in a static laboratory setting 19,20 and hence provides more pedestrian environmental elements (See Table 1 for a brief summary). Further, in the studies discussed above, the effect of descending steps on gaze behaviour has not been investigated, despite their prevalence in the built environment. This study aims to establish the effect of light level and step-heights on pedestrians' gaze behaviour and how far ahead on the pavement pedestrians start their visual fixation on the upcoming step (detection distance). One key rationale of this study is that older people's gaze behaviour and detection distance need to be studied alongside young people in a simulated pedestrian environment in order to understand the impact of pedestrian environment on older people's ability to detect steps during walking. 


\section{Method}

\subsection{Participants}

Following ethical approval by the University College London (UCL) Research Ethics Committee, 16 healthy young participants ( $25-34$ years old) and 15 healthy older participants (65 - 74 years old) were recruited for this study. All participants were screened using the mini-mental state examination (MMSE) and Fall Efficacy Scale International (FESI) to check their cognitive function and degree of fear of falling, so that they were not being put at the risk of falling during the experiment. Two clinical fall risk assessment tools, 180 degree turn and Timed-Up-and-Go test (TUG), were also performed ${ }^{23}$. The $180^{\circ}$ turn test requested each participant to stand and step halfway around $\left(180^{\circ}\right)$. The number of steps each participant made was recorded. The TUG test requested each participant to stand up from a chair without any external aids, walk 3 metres at a self-selected pace, turn around, walk and sit back down. The time for completing the TUG test was recorded. Those who had any known balance or visual impairment affecting their gait and posture, or made the $180^{\circ}$ turn test using more than 5 steps, or completed the Timed Up and Go test in more than 13.5 sec were considered to have higher risk of falling and therefore would excluded from the experiments. Participants were asked to take the visual acuity test and Pelli-Robson contrast sensitivity test to ensure that they had no visual impairment affecting contrast detection. All participants passed the screenings and reported no known mobility difficulty or visual impairment affecting their daily living.

\subsection{Experimental setup}

A walkway was set up at the Pedestrian Accessibility Movement Environment Laboratory (PAMELA) at UCL (Figure 1). The pedestrian platform at PAMELA consists of adjustable modules that can be raised, lowered and sloped to create different topographies. The walkway surface was standard concrete chamfered paving slabs reproducing generic pavements in the UK and was walled by blackout cloth and screens to remove surrounding distractions within the laboratory (Figure 2). A step was set up $2.4 \mathrm{~m}$ before the end of the walkway. This location was chosen to maximise the effective length of the approach phase, yet ensure that the length of the walkway after the step-encountering would still be sufficient not to disturb walking behaviour before and/or during the step. A starting line was set up 1.2 $\mathrm{m}$ from the start of the walkway, making the approach phase $13.2 \mathrm{~m}$ overall. 


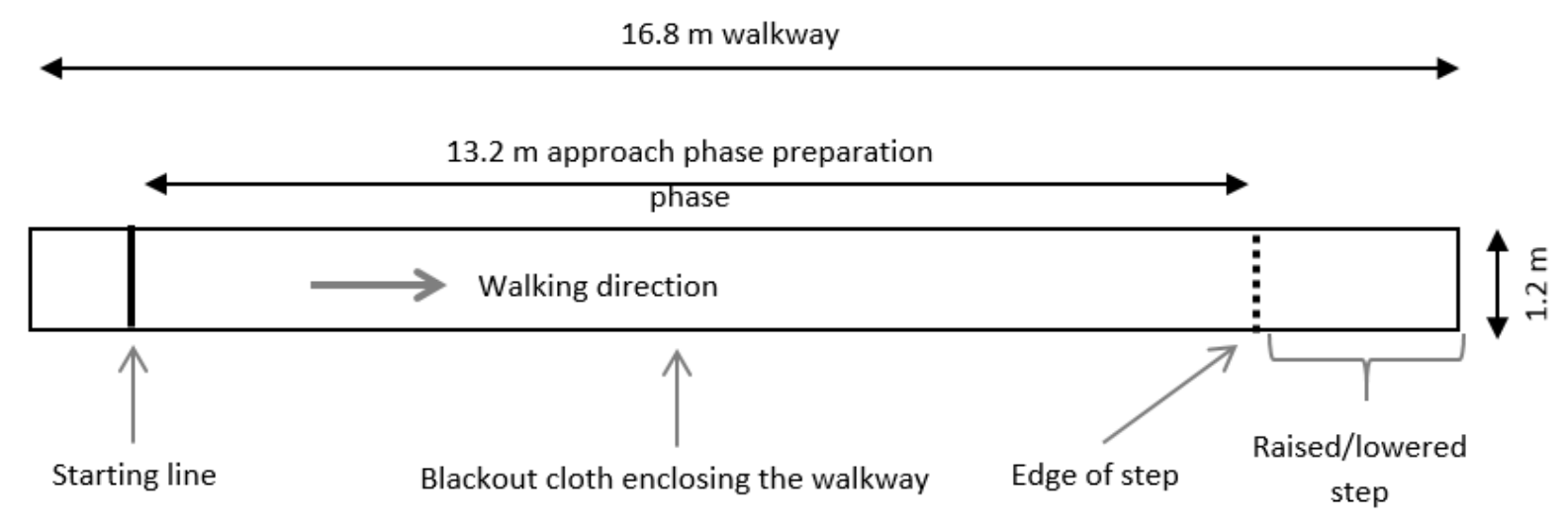

Figure 1. Schematic diagram of the experimental setup

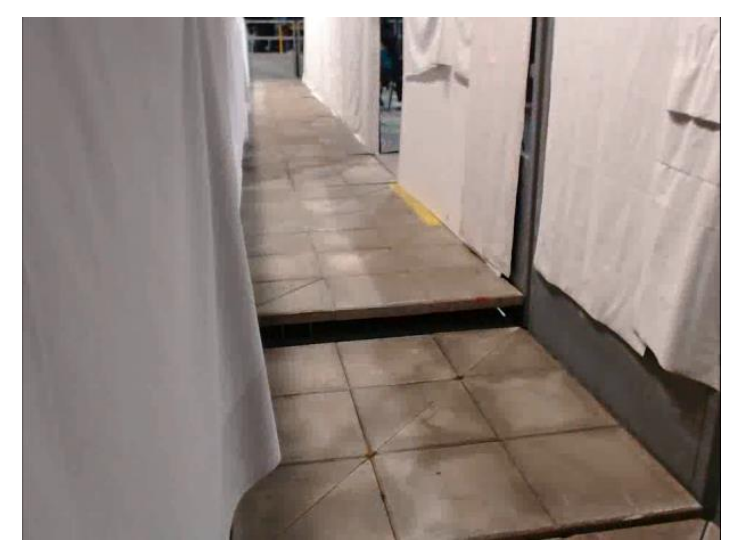

Figure 2. The experimental setup captured by a camera positioned at the end of the walkway. In this task, participants were about to walk along the walkway containing a $-125 \mathrm{~mm}$ step (descending step).

Two light levels were set up in this study, 4 Ix (provided by high pressure sodium lamps) and $200 \mathrm{~lx}$ (provided by fluorescent lamps), representing the minimum and acceptable illuminance for general street lighting as described in standards and guidelines 11,14. These illuminances refer to the mean horizontal illuminance defined in lighting standards and measured using a Konica Minolta Illuminance Meter T-10 on the floor and averaged from all readings in the centre of each of the $1.2 \mathrm{~m}$ by $1.2 \mathrm{~m}$ concrete paving slab modules. The luminance on the floor observed from participants' eye height were measured as $0.2 \mathrm{~cd} / \mathrm{m}^{2}$ and $10 \mathrm{~cd} / \mathrm{m}^{2}$, approximately, at $4 \mathrm{~lx}$ and $200 \mathrm{~lx}$, respectively. The boundary between mesopic and photopic vision is about $3-5 \mathrm{~cd} / \mathrm{m}^{2}$. Four heights of descending steps (steps down from the approach phase level) were used: -125, -90, -60 and -30 mm; ascending steps (steps up) with the same heights were also used. The step-height of $30 \mathrm{~mm}$ is the threshold between moderate and hazardous defects on the pavement ${ }^{24}$ and $125 \mathrm{~mm}$ is the minimum height of a standard kerb ${ }^{14}$. An interval about $30 \mathrm{~mm}$ was chosen as an initial study and also to avoid participants' fatigue caused by too much walking. 


\subsection{Procedure}

Participants were asked to walk along the walkway at their own comfortable pace. Three walking trials, as practice, were performed by the participants to familiarise themselves with the environment and task. In the experiment itself, participants were asked to walk up and down the walkway three times encountering either an ascending or descending step. The order of the step-heights was randomised. A trial was defined as when participants completed the approach phase of $13.2 \mathrm{~m}$. The completion of the trial was marked by a bespoke light gate. The light gate consisted of a set of retroreflective sensors and reflectors set up at $56.5 \mathrm{~cm}$, about individual's knee height, above the level of and at the end of the approach phase. Data received from the light gate was recorded by Labview 2013 (National Instruments) with a sampling frequency of $1000 \mathrm{~Hz}$.

\subsection{Data collection}

The light-weight binocular SMI GazeWear (SensoMotoric Instruments Inc.) eye tracking glasses with a sampling frequency of $30 \mathrm{~Hz}$ was used to capture visual fixations (Figure 3). The data was stored locally on a recording unit the size of a smart phone worn by participants and then downloaded through the eye tracking analysis software SMI BeGaze (SensoMotoric Instruments Inc.) for further data analysis. The field of view of the frontal scene camera is $1024 \times 768$ in pixels, corresponding to 60 degrees horizontal and 46 degrees vertical. The accuracy of gaze position is within 0.5 degree. A minimum fixation duration of 99 ms within 100 pixel dispersion was used as criterion to define a visual fixation 16.

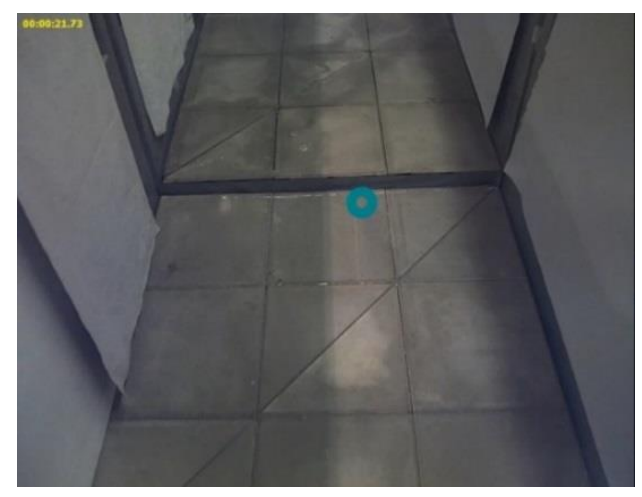

Figure 3. A frame of a visual fixation on a $+60 \mathrm{~mm}$ step recorded by the eye tracker.

\subsection{Data analysis}

The pedestrian environmental factors, consisted of light level, step-height and age were fixed factors. The duration of each trial - from the starting point to the end of the 13.2 
m approach phase (trial time: seconds), the distance between where the participant was when the first visual fixation happened in relation to the location of the step (detection distance: $m$ ), number of fixations in each trial (number of fixations) and the proportion of the overall fixation duration in each trial to the trial time (fixation duration: \%) were dependent variables. The first visual fixation was defined as the first visual fixation registered after each trial started. The detection distance was calculated by multiplying the time period between the happening of the first fixation and the completion of each trial by the mean walking speed for each trial. Only the visual fixations happening in the approach phase were analysed.

A factorial analysis of variance (ANOVA) with $p=0.05$ significance levels corrected by the Bonferroni adjustment and Tukey's honest significant difference (HSD) for post-hoc comparison tests were used. Not all data in this paper met the assumption of the normality of distribution but previous research in statistical analysis ${ }^{25,26}$ suggested that if the violation is moderate, the data set is small and the assumption of homogeneity of variance is not violated, ANOVA is robust. Datasets in this paper that did not meet the assumption of normality of distribution all satisfied the abovementioned criteria and therefore ANOVA was still applicable in the present analysis instead of conducting a series of non-parametric tests, which would lead to possible type I error.

\section{Results}

Lighting level was a significant factor in older participants' trial time and detection distance (Figure 4). Among older participants, at 4 lux both the trial time $(s)(m=11.61, S D=1.68)$ and detection distance $(m)(m=3.45, S D=1.74)$ were significantly shorter than at 200 lux ( $\mathrm{m}=11.89, \mathrm{SD}=1.95 ; \mathrm{m}=3.94, \mathrm{SD}=1.96$; with $p=0.022$ and $p<0.001$, respectively). At both 200 lux and 4 lux, older participants had significantly shorter detection distance $(m)(m=3.94$, $S D=1.96 ; m=3.45, S D=1.74)$ than young participants $(m=4.71, S D=2.13 ; m=4.85, S D=2.00$; with $p<0.001$ and $p<0.001$, respectively). At both 200 lux and 4 lux, older participants had significantly greater number of fixations $(m=5.66, S D=5.23 ; m=5.91, S D=5.31)$ than young participants ( $\mathrm{m}=4.80, \mathrm{SD}=4.68 ; \mathrm{m}=5.23, \mathrm{SD}=4.74$; with $p<0.001$ and $p=0.024$, respectively). At both 200 lux and 4 lux, older participants had significantly longer fixation duration (\%) $(m=5.66, S D=5.23 ; m=5.91, S D=5.31)$ than young participants $(m=4.80, S D=4.68 ; m=5.23$, $\mathrm{SD}=4.74$; with $p=0.015$ and $p=0.037$ respectively). 

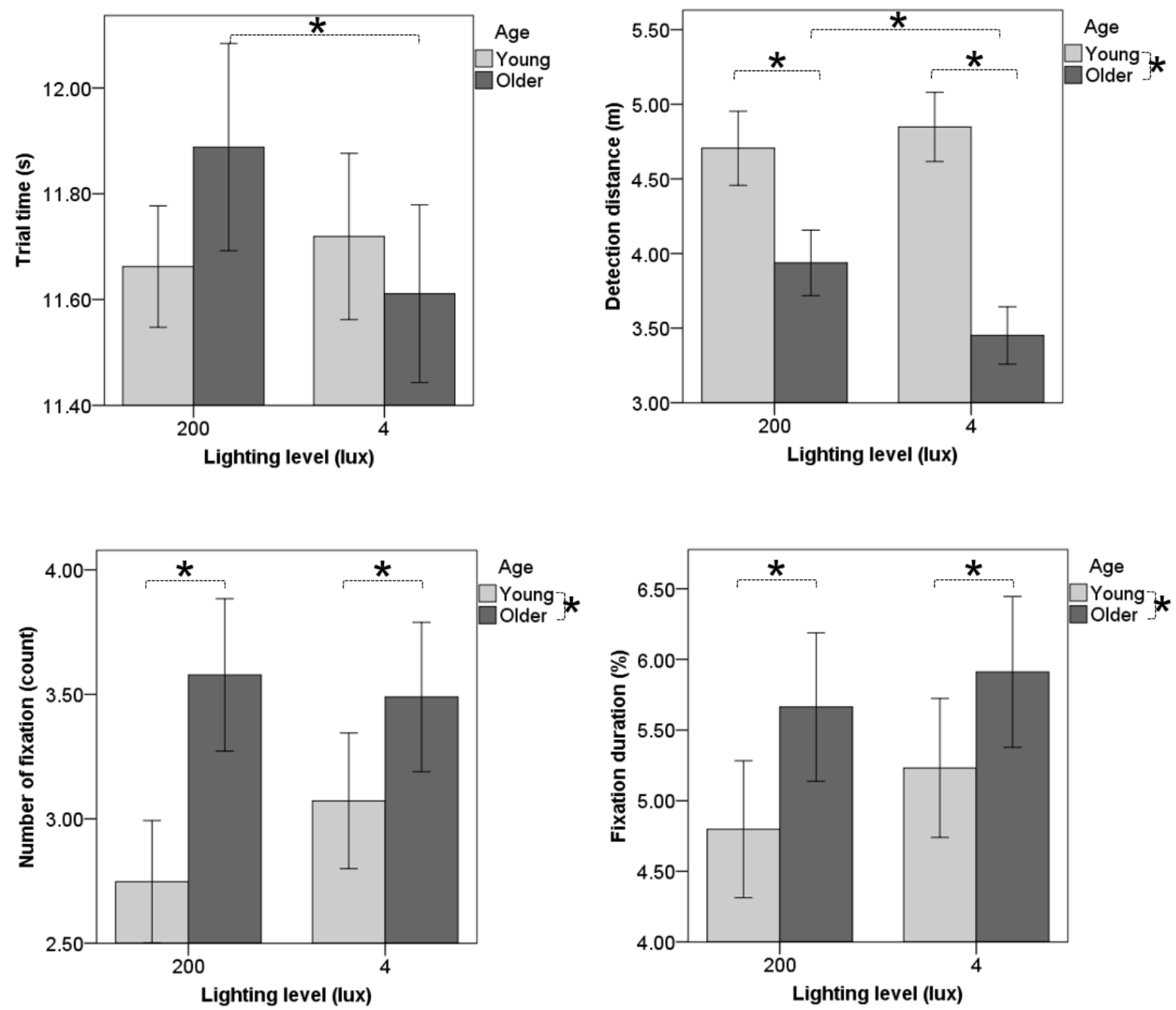

Figure 4. The effect of light level on trial time, detection distance, number of fixations and fixation duration between and among age groups ( ${ }^{*}$ means a statistically significant difference $p<0.05$ ). Error bar: $95 \%$ confidence interval.

Step-height was a significant factor in young participants' number of fixations (Figure 5). Among young participants, the number of fixations on $-90 \mathrm{~mm}(\mathrm{~m}=2.40, \mathrm{SD}=2.02)$ and $60 \mathrm{~mm}(\mathrm{~m}=2.34, \mathrm{SD}=2.10)$ was significantly lower than $+125 \mathrm{~mm}(\mathrm{~m}=3.66, \mathrm{SD}=3.03$; with $p=0.017$ and $p=0.014$, respectively). 


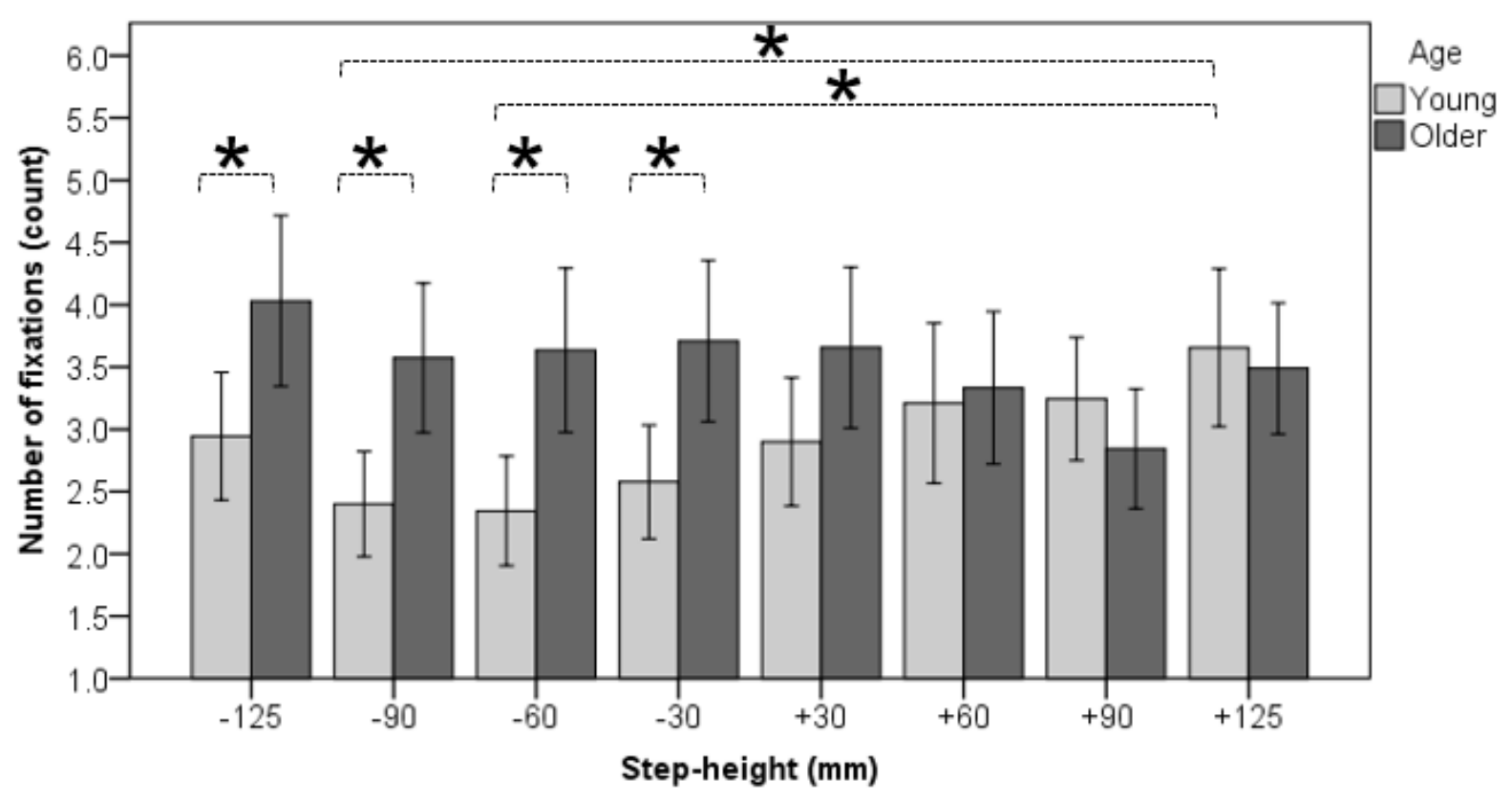

Figure 5. The effect of step-height on the number of fixations between and within age groups ( ${ }^{*}$ means a statistically significant difference $p<0.05)$. Error bar: $95 \%$ confidence interval.

A statistically significant age difference was found in some descending steps at which older participants' number of fixations (Figure 5) and fixation duration (\%) (Figure 6) were less than for young participants. The number of fixations of older participants at $-125 \mathrm{~mm}$ ( $m=4.03, S D=3.39),-90 \mathrm{~mm}(\mathrm{~m}=3.57, \mathrm{SD}=2.97),-60 \mathrm{~mm}(\mathrm{~m}=3.64, \mathrm{SD}=3.26)$ and $-30 \mathrm{~mm}$ $(m=3.71, S D=3.20)$ was greater than that of young participants $(m=2.94, S D=2.45 ; m=2.40$, $\mathrm{SD}=2.02 ; \mathrm{m}=2.34, \mathrm{SD}=2.10 ; \mathrm{m}=2.58, \mathrm{SD}=2.18$; with $p=0.006, p=0.003, p=0.001$ and $p=0.004$, respectively). The fixation duration (\%) of older participants at $-90 \mathrm{~mm}(\mathrm{~m}=6.02$, $\mathrm{SD}=5.57)$ and $-60 \mathrm{~mm}(\mathrm{~m}=5.93, \mathrm{SD}=5.52)$ was longer than that of young participants ( $\mathrm{m}=4.07, \mathrm{SD}=3.54 ; \mathrm{m}=3.91, \mathrm{SD}=4.02$; with $p=0.007$ and $p=0.004$ respectively). 


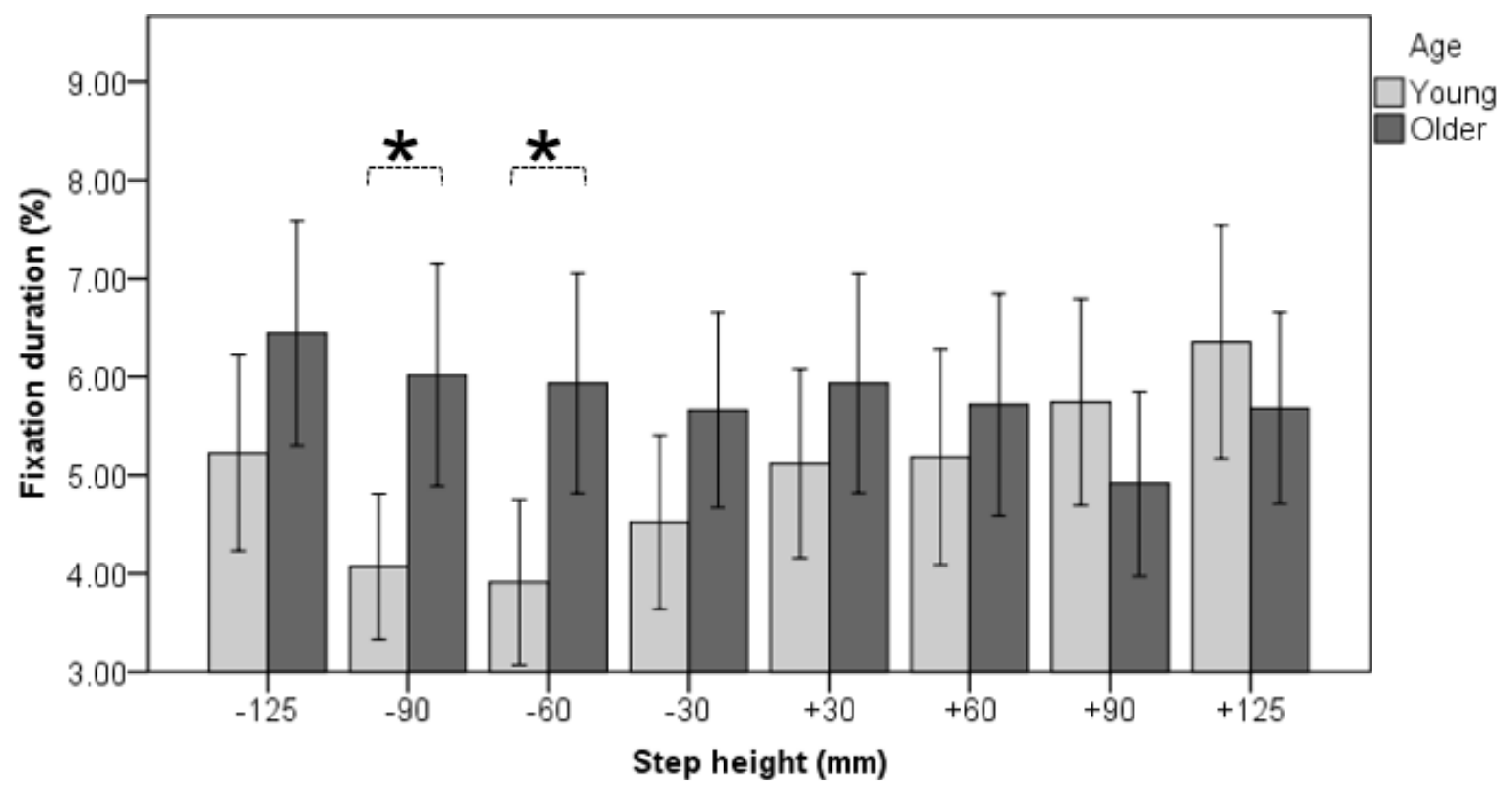

Figure 6. The effect of step-heights on the fixation duration between young and older age groups (* means a statistically significant difference $p<0.05)$. Error bar: $95 \%$ confidence interval.

Age was a significant factor in the detection distance, number of fixations and fixation duration (Figure 4). Older participants had shorter detection distance $(m)(m=3.69, S D=1.87)$ than young participants $(m=4.77, S D=2.07$; with $p<0.001)$. Older participants had a greater number of fixations and fixation duration $(\%)(m=3.53, S D=3.02 ; m=5.79, S D=5.27)$ than young participants $(m=2.91, S D=2.51 ; m=5.01$, $S D 4.71$; with $p<0.001$ and $p=0.001$, respectively).

\section{Discussion}

The aim of this study was to understand older people's requirements for an accessible pedestrian environment by investigating their detection distance, trial time and gaze behaviour at different light levels and step-heights. The results suggest that light level affects older people's trial time and detection distance. A descending step was found to be a key factor in the difference in number of fixations and fixation duration between young and older people. Age differences were also revealed in detection distance, number of fixations and fixation duration. Due to the age-related changes in vision ${ }^{8,9}$ older people have a shorter detection distance, suggesting that they may start the first visual fixation later in the lower lighting environment. Therefore, the illuminance that can provide older pedestrians with 
enough visual information to detect the upcoming step in the street lighting environment may be higher than that of young pedestrians.

The longer trial time in the higher lighting environment of 200 lux for older people indicates that older people may walk slower at 200 lux than 4 lux. This finding seems counterintuitive as the contrast between floor and step at 200 lux is greater than that of 4 lux, hence the upcoming step, along with other trip hazards, should be better anticipated and identified at 200 lux. One of the reasons might be that the shadows on the pavement caused by the blackout clothes in the brighter lighting environment divided older people's visual attention, resulting in a slower walking speed at 200 lux. However, young people's walking speed may not be affected by shadows on the pavement caused by the brighter lighting level.

The detection distance for both age groups (4.78 $\mathrm{m}$ for young and $3.69 \mathrm{~m}$ for older people) provides an alternative to the investigation of object detection in past studies. It not only reveals that older people have shorter detection distance than young people but also suggests a set of distances that can be further discussed or used in the pedestrian environment design process.

Step-height affects young people's number of fixations due in part to the ambiguity of the visual presence of descending steps so that visual fixation happens less frequently ${ }^{27}$. However, there may be difference in visual demand among descending steps as $-125 \mathrm{~mm}$ is not the least fixated height whereas -90 and $-60 \mathrm{~mm}$ are significantly less fixated than $+125 \mathrm{~mm}$.

When approaching a step, older people have greater number of fixations and fixation duration than young people. The result suggests that older people may be constantly aware of the upcoming step on the pavement, regardless its height and direction, either ascending or descending, and therefore a constant amount of visual information of the step is required to possibly pre-plan and implement foot adjustment. It can also help explain why step-height affects the gaze behaviour of young people only. Previous studies in obstacle detection $6,17,19,20$ considered only the obstacles above ground level and this study reveals that descending steps may be perceived as more visually demanding by older people than young people.

Age has a significant effect on detection distance, number of fixations and fixation duration in which older people have shorter detection distance, greater number of fixations as well as longer fixation duration than young people. This reveals that older people, as opposed to young people, are less efficient in processing visual information about the step 
negotiation. The result of the reduced processing efficiency for visual information of older people is in line with Chapman and Hollands' ${ }^{28,29}$ finding of the consequence of age-related decline in the central nervous system's visuomotor processing. By processing the same amount of visual information about the step with less efficiency using the degenerated physiology, older people may be considered to be more vulnerable to the steps on the pavement as well as lower light levels in the pedestrian environment. Older people showing shorter detection distance are also more cautious about the immediate surroundings, regardless of the visual presence of the upcoming step, as opposed to young people.

It should be pointed out that the approach developed in this study has engaged both the sensory and physical capabilities of older people with the pedestrian environmental factors of light levels and step-heights, which was not fully done in past studies. The laboratory based testing environment in some past studies ${ }^{19,20}$ may be too static to simulate pedestrian environment. Therefore, this study has established an approach of simulating the pedestrian environment to investigate pedestrians' gaze behaviour and detection distance. The results of this study suggest that the effect of light level and step-height on trial time, detection distance and gaze behaviour may put older people more at risk of a trip hazard than young people.

We do, however, acknowledge several limitations of this paper. As an initial study exploring the effect of pedestrian environmental factors on how older people detect an upcoming step during walking based on official pavement design guidelines, only eight heights and two light levels were set up. There were only two age groups from an overall 30 participants recruited, which though this can establish the age difference, is not able to reveal the change in walking and visual perception in relation to the process of ageing. Therefore a larger sample size across all age groups will be needed for further studies. Further studies are also suggested to investigate the optimum lighting for older people and their psychological and biomechanical reaction to descending steps on the pavement.

\section{Conclusion}

Understanding how light level and step-height affect pedestrian's trial time, detection distance and gaze behaviour is fundamental to improving the accessibility of the pedestrian environment. Thirty-one participants (16 older and 15 young) performed walking trials of eight step-heights at two light levels in the simulated pedestrian environment. The analyses 
of visual fixation on the upcoming step during walking have helped investigate how older people can be affected by pedestrian environmental factors.

In the lower lighting environment, older people have shorter trial times as well as detection distances due in part to degenerated vision. Descending steps are more visually demanding for older people than young people. The detection distance of older people is shorter, as opposed to young people. This may be explained as older people are less efficient in processing visual information about the upcoming step on the pavement.

This study provides a new approach to investigate walking behaviour and visual perception in different pedestrian environment settings. The results of this study reveal that the interaction between older people and environmental factors is different from that of young people in the pedestrian environment. Hence the pedestrian environment, as part of the outdoor built environment, should be designed inclusively considering the need of older people as one of the user groups with higher vulnerability.

\section{Declaration of Conflicting Interests}

The Authors declare that there is no conflict of interest.

\section{Funding}

\section{Acknowledgements}

The authors gratefully acknowledge the technical support of the research technicians, researchers and manager of the Pedestrian Accessibility Movement Environment Laboratory of the University College London.

\section{References}

1. Help the Aged. Preventing Falls Retrieved from http://www.ageuk.org.uk/documents/en-gb/for-professionals/health-andwellbeing/id6910_preventing_falls_2007_pro.pdf?dtrk=true. 
2. Sonmez TH, Malkoc YE, Altug I. Evaluation of elderly people's requirements in public open spaces: A case study in Bornova District (Izmir, Turkey). Building and Environment 2007; 42: 2035-2045.

3. Burton E, Mitchell L. Inclusive Urban Design: Streets For Life. Oxford: Routledge, 2006.

4. Inclusive Design for Getting Outdoors. I'DGO Design Guides. Retrieved from http://www.idgo.ac.uk/design_guidance/index.htm (2007).

5. Raynham P. An examination of the fundamentals of road lighting for pedestrians and drivers. Lighting Research and Technology 2004; 36: 307-313.

6. Uttley J, Fotios S, Cheal C. Effect of illuminance and spectrum on peripheral obstacle detection by pedestrians. Lighting Research and Technology First published 22 September 2015, doi 1477153515602954.

7. Fotios S, Uttley J. Illuminance required to detect a pavement obstacle of critical size. Lighting Research and Technology First published 20 July 2016, doi 1477153516659783.

8. Campbell S. Deteriorating Vision, Falls and Older People: The Links. Glasgow, UK: Visibility.

9. Lord SR, Dayhew J. Visual risk factors for falls in older people. Journal of the American Geriatrics Society 2001; 49: 508-515.

10. Darowski A. Falls: The Facts. Oxford: Oxford University Press, 2008.

11. The Chartered Institution of Highways and Transportation. Manual for Streets 2. London: Retrieved 25 May 2016 from https://www.gov.uk/government/publications/manual-for-streets-2.

12. British Standards Institution. Code of Practice for the Design of Road Lighting. Lighting of Roads and Public Amenity Areas. BS 5489-1:2013. London: BSI, 2012.

13. British Standards Institution. Road Lighting. Performance Requirements. BS EN 132012:2003. London: BSI, 2003.

14. Department for Transport. Inclusive Mobility. Retrieved 15 December 2010 from thttp://www.dft.gov.uk/transportforyou/access/peti/inclusivemobility.

15. Pickett A, Gallagher A. The Ukpms User Manual Volume 2. PCIS Support Contract, Retrieved from http://www.pcis.org.uk/index.php?p=6/12/0/detail,0,644.

16. Patla AE, Vickers JN. Where and when do we look as we approach and step over an obstacle in the travel path? Neuroreport 1997; 8: 3661-3665.

17. Patla A, Vickers J. How far ahead do we look when required to step on specific locations in the travel path during locomotion? Experimental Brain Research 2003; 148: 133-138.

18. Marigold DS, Patla AE. Gaze fixation patterns for negotiating complex ground terrain. Neuroscience 2007; 144: 302-313.

19. Fotios S, Cheal C. Obstacle detection: A pilot study investigating the effects of lamp type, illuminance and age. Lighting Research and Technology 2009; 41: 321-342. 
20. Fotios S, Cheal C. Using obstacle detection to identify appropriate illuminances for lighting in residential roads. Lighting Research and Technology 2013; 45: 362-376.

21. Hausdorff JM, Nelson ME, Kaliton D, Layne JE, Bernstein MJ, Neurnberger A, Singh MA. Etiology and modification of gait instability in older adults: a randomized controlled trial of exercise. Journal of Applied Physiology 2001; 90: 2117-2129.

22. Hausdorff JM. Gait variability: methods, modeling and meaning. Journal of NeuroEngineering and Rehabilitation 2005; 2: 19.

23. National Institute for Health and Care Excellence. Clinical Knowledge Summaries: Falls - Risk Assessment. Retrieved 22 January 2013 from http://www.cks.nhs.uk/falls_risk_assessment/evidence/supporting_evidence/up_go_tes t_and_turn_180o_test\#.

24. Murray MP. Gait as a total pattern of movement. American Journal of Physical Medicine 1967; 46: 290-333.

25. Montgomery DC. Design and Analysis of Experiments. 8th edition. Hoboken, NJ: John Wiley and Sons, 2012.

26. Zar JH. Biostatistical Analysis. 5th edition. Upper Saddle River, NJ: Pearson, 2009.

27. Miyasike-daSilva V, Mcllroy WE. Does it really matter where you look when walking on stairs? Insights from a dual-task study. PLOS ONE 2012; 7: e44722.

28. Chapman GJ, Hollands MA. Evidence for a link between changes to gaze behaviour and risk of falling in older adults during adaptive locomotion. Gait and Posture 2006; 24: 288-294.

29. Chapman GJ, Hollands MA. Evidence that older adult fallers prioritise the planning of future stepping actions over the accurate execution of ongoing steps during complex locomotor tasks. Gait and Posture 2007; 26: 59-67.

\section{Figure captions}

Figure 1. Schematic diagram of the experimental setup

Figure 2. The experimental setup captured by a camera positioned at the end of the walkway. In this task, participants were about to walk along the walkway containing a $125 \mathrm{~mm}$ step (descending step).

Figure 3. A frame of a visual fixation on a $+60 \mathrm{~mm}$ step recorded by the eye tracker.

Figure 4. The effect of light level on trial time, detection distance, number of fixations and fixation duration between and among age groups (* means a statistically significant difference $p<0.05)$. Error bar: $95 \%$ confidence interval. 
Figure 5. The effect of step-height on the number of fixations between and within age groups ( ${ }^{*}$ means a statistically significant difference $\left.p<0.05\right)$. Error bar: $95 \%$ confidence interval.

Figure 6. The effect of step-heights on the fixation duration between young and older age groups ( ${ }^{*}$ means a statistically significant difference $p<0.05$ ). Error bar: $95 \%$ confidence interval. 
Table 1. Past experiments on the effects of light level and step-height on the detection or fixation distance

\begin{tabular}{|c|c|c|c|c|c|c|}
\hline Study & $\begin{array}{l}\text { Method\& obstacle } \\
\text { detection }\end{array}$ & Participants & Illuminances & $\begin{array}{l}\text { Heights of } \\
\text { obstacle or } \\
\text { step }\end{array}$ & $\begin{array}{l}\text { Detection or } \\
\text { fixation distance }\end{array}$ & $\begin{array}{l}\text { Optimum } \\
\text { illumnan } \\
\text { ce }\end{array}$ \\
\hline $\begin{array}{l}\text { Patla \& } \\
\text { Vickers } \\
16\end{array}$ & $\begin{array}{l}\text { Walking task with } \\
\text { eye tracker; } \\
\text { obstacles placed 4- } \\
6 \mathrm{~m} \text { ahead }\end{array}$ & Eight & n.a. ${ }^{*}$ & $\begin{array}{l}+10,+150 \text { and } \\
+300 \mathrm{~mm}\end{array}$ & $\begin{array}{l}\text { Fixation till one } \\
\text { or two steps } \\
\text { before the } \\
\text { obstacle }\end{array}$ & n.a. \\
\hline $\begin{array}{l}\text { Fotios \& } \\
\text { Cheal }{ }^{19}\end{array}$ & $\begin{array}{l}\text { Static using forced- } \\
\text { choice method; } \\
\text { raised obstacles in } \\
\text { a single booth }\end{array}$ & $\begin{array}{l}\text { Twenty one, } \\
11 \\
\text { young(<45yo) } \\
\text { and } 10 \\
\text { old(>60yo) }\end{array}$ & $\begin{array}{l}0.2,2.0 \text { and } \\
20 \text { lux }\end{array}$ & $\begin{array}{l}\text { Eight heights } \\
\text { between }+0.40 \\
\text { and }+7.94 \mathrm{~mm}\end{array}$ & n.a. & 2.0lux \\
\hline $\begin{array}{l}\text { Fotios \& } \\
\text { Cheal } 20\end{array}$ & $\begin{array}{l}\text { Static using forced- } \\
\text { choice method; } \\
\text { raised obstacles in } \\
\text { a single booth }\end{array}$ & $\begin{array}{l}\text { Four, aged } \\
18-34\end{array}$ & $\begin{array}{l}0.20,0.63, \\
2,6.32 \text { and } \\
20 \text { lux }\end{array}$ & $\begin{array}{l}\text { Six heights } \\
\text { between }+0.40 \\
\text { and }+6.31 \mathrm{~mm}\end{array}$ & $\begin{array}{l}6 \mathrm{~m}, \text { for an } \\
\text { obstacle of } \\
\text { height } 25 \mathrm{~mm} \text { at } \\
1.8 \text { lux }\end{array}$ & 2.0lux \\
\hline $\begin{array}{l}\text { Uttley et } \\
\text { al. }{ }^{6}\end{array}$ & $\begin{array}{l}\text { Treadmill walking } \\
\text { with divided } \\
\text { attention: peripheral } \\
\text { vision; raised } \\
\text { objects placed } 2.6 \mathrm{~m} \\
\text { ahead }\end{array}$ & $\begin{array}{l}\text { Thirty, } \\
\text { including } 15 \\
\text { younger } \\
\text { (<35yo) and } \\
15 \text { older } \\
(>50 \text { yo) }\end{array}$ & $\begin{array}{l}0.2,0.6,2.0 \\
6.3 \text { and } 20 \\
\text { lux }\end{array}$ & $\begin{array}{l}\text { Seven heights } \\
\text { between } \\
+0.5 \mathrm{~mm} \text { and } \\
+28.4 \mathrm{~mm}\end{array}$ & $\begin{array}{l}2.6 \mathrm{~m} \text { of fixation } \\
\text { distance }\end{array}$ & 2.0lux \\
\hline
\end{tabular}

${ }^{\star}$ Note: n.a. $=$ not available. 


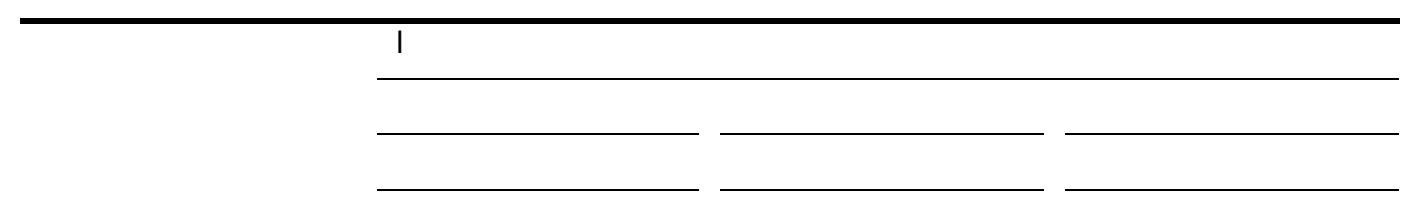


